\title{
Apontamentos sobre a história do mercado sergipano de televisão
}

\author{
Cesar Ricardo Siqueira BOLAÑO ${ }^{1}$ \\ Demétrio Rodrigues VARJÃO² \\ Bruna TÁVORA ${ }^{3}$ \\ Ana Carolina WESTRUP ${ }^{4}$ \\ Pedro Alexandre de Oliveira SANTOS ${ }^{5}$ \\ Joanne Santos MOTA ${ }^{6}$ \\ Werden Tavares PINHEIRO ${ }^{7}$ \\ AntonioVinícius Oliveira GONÇALVES ${ }^{8}$ \\ Luzileide Silva SANTOS ${ }^{9}$ \\ Rafael Saldanha ROCHA ${ }^{10}$
}

Resumo:

Este trabalho sintetiza uma análise mais completa sobre o mercado de televisão no Estado de Sergipe, apresentada no livro Mercado Brasileiro de Televisão em perspectiva regional: o caso de Sergipe (BOLAÑO; VARJÃO, 2016), produzido pelo Observatório de Economia e Comunicação da Universidade Federal de Sergipe, o qual faz parte de um projeto maior, de retomada do estudo sobre o sistema brasileiro de televisão, em perspectiva agora regional - ao contrário da sua matriz original (BOLAÑO, 1988) - e numa situação bastante transformada pelo avanço da convergência telecomunicações/audiovisual/informática e pela expansão da Internet. Neste artigo trataremos apenas de aspectos históricos da TV aberta sergipana, trazendo elementos desde a implantação da radiodifusão no estado em 1939, passando pelo início da TV aberta na segunda metade da década de 1960, alcançando as principais tendências das emissoras de TV aberta nas últimas décadas. $\mathrm{O}$ resultado a que chegamos foi um panorama histórico sintético da TV aberta em Sergipe que contribui para os estudos sobre história da mídia no Brasil em perspectiva regional.

Palavras-chave:

\footnotetext{
${ }^{1}$ Doutor em Ciência Econômica pela Universidade Estadual de Campinas. Professor associado IV da Universidade Federal de Sergipe (UFS) e coordenador do Observatório de Economia e Comunicação da Universidade Federal de Sergipe (OBSCOM/Cepos-UFS). Email: bolano.ufs@ gmail.com.

2 Mestre no Programa de Pós-Graduação em Comunicação da Universidade Federal de Sergipe. Pesquisador do OBSCOM/Cepos. Email: demetriovarjao@gmail.com.

3 Mestre no Programa de Pós-Graduação em Comunicação da Universidade Federal de Sergipe. Professora substituta do curso de Comunicação Social da UFS e pesquisadora do OBSCOM/Cepos. Email: tavora.bruna@gmail.com.

4 Mestre no Programa de Pós-Graduação em Comunicação da Universidade Federal de Sergipe. Pesquisadora do OBSCOM/Cepos. E-mail: anacwestrup@yahoo.com.br.

5 Mestrando no Programa de Pós-Graduação em Comunicação da Universidade Federal de Sergipe. Pesquisador do OBSCOM/Cepos. Email: psester@gmail.com.

${ }^{6}$ Mestranda no Programa de Pós-Graduação em Comunicação da Universidade Federal de Sergipe. Pesquisadora do OBSCOM/Cepos. E-mail: joannemota@gmail.com.

${ }^{7}$ Mestre no Programa de Pós-Graduação em Comunicação da Universidade Federal de Sergipe. Professor substituto do curso de Comunicação Social da UFS e pesquisador do OBSCOM/Cepos. E-mail: werden@gmail.com.

${ }^{8}$ Mestrando no Programa de Pós-Graduação em Comunicação da Universidade Federal de Sergipe. Pesquisador do OBSCOM/Cepos. E-mail: vinicius.socialismo@gmail.com.

${ }^{9}$ Mestranda no Programa de Pós-Graduação em Comunicação da Universidade Federal de Sergipe. Email: pitangaazul@gmail.com.

${ }^{10}$ Graduando em Economia pela Universidade Federal de Sergipe. E-mail: rafa_san17@hotmail.com.
} 
História da mídia regional. Mercado sergipano de televisão. Economia Política da Comunicação.

\title{
Notes on the history of the sergipan television market
}

\begin{abstract}
:
This paper synthetizes a broader analysis about the Television Market in the state of Sergipe, presented in the book Brazilian Television Market in regional perspective: the sergipan case (BOLÃNO; VARJÃO, 2016), made by the Communication and Economics Observatory of the Federal University of Sergipe, which is part of a bigger project, that reviews the study about the brazilian television system, now in a regional - as opposite to It's original matrix (BOLÃNO, 1988) - perspective, and in a situation highly transformed by the advance of the convergence telecomunications/audiovisual/networking and by the expansion of the internet. In this paper we will discuss only the historical aspects of sergipan open TV, bringing elements since the implementation of broadcasting in the state in 1939, going through the beginning of open TV on the second half of 1960's decade, until we reach the principal tendencies of open TV networks in the last decades. The results that we came across gave us a synthetic historical landscape of the open TV in the state of Sergipe that contributes to the studies on media history in Brazil in a regional perspective.
\end{abstract}

Keywords:

History of regional media. Sergipan television market. Political Economy of Communication.

\section{Apuntes sobre la historia del mercado sergipano de televisión}

\begin{abstract}
Resumen:
Este trabajo sintetiza un análisis más completo sobre el mercado de televisión en el Estado de Sergipe, presentada en el libro Mercado Brasileño de Televisión en perspectiva regional: el caso de Sergipe (BOLAÑO; VARJÃO, 2016), producido por el Observatorio de Economía y Comunicación de la Universidad Federal de Sergipe. Este forma parte de un proyecto mayor, de reanudación del estudio sobre el sistema brasileño de televisión, ahora en perspectiva regional - al contrario de su matriz nacional, original en Bolaño (1988) y en una situación bastante transformada por el avance y la evolución de la convergencia de las telecomunicaciones / audiovisual / informática y por la expansión de Internet. En este artículo trataremos sólo de aspectos históricos de la televisión abierta sergipana.

Palabras clave:

Historia de los medios de comunicación regional. Mercado sergipano de televisión. Economía Política de la Comunicación.
\end{abstract}

\section{INTRODUÇÃO}

Este trabalho sintetiza uma análise mais completa sobre o mercado de televisão no Estado de Sergipe, apresentada no livro Mercado Brasileiro de Televisão em perspectiva regional: o caso de Sergipe (BOLAÑO; VARJÃO, 2016), produzido pelo Observatório de Economia e Comunicação da Universidade Federal de Sergipe, o qual faz parte de um projeto maior, de retomada do estudo sobre o sistema brasileiro de televisão, em perspectiva agora regional - ao contrário da sua matriz original (BOLAÑO, 1988) - e numa situação bastante transformada pelo avanço da convergência telecomunicações/audiovisual/informática e pela expansão da Internet. Neste artigo trataremos apenas de aspectos históricos da TV aberta sergipana. 
A posição subalterna e dependente que a economia brasileira historicamente ocupa na divisão internacional do trabalho nos dá a chave para compreender as razões da adoção de determinados paradigmas para o desenvolvimento dos seus sistemas industriais, que em geral vão no sentido de atender às necessidades das empresas oligopolistas nacionais e internacionais. No caso das indústrias culturais e da comunicação também é assim.

O Diagrama 1, extraído de Bolaño (2007), apresenta os encadeamentos das relações fundamentais entre a produção, sobretudo internacional, hegemônica, os meios de difusão e distribuição nacionais e sua implantação no espaço local. Cada um dos setores de produção considerados (espetáculo esportivo, artes do espetáculo ao vivo, edição audiovisual, incluindo cinema e vídeo, edição fonográfica, edição do livro e imprensa, incluindo jornais e revistas) se estrutura sob a forma de oligopólio, mais ou menos concentrado, mais ou menos internacionalizado.

A terceira coluna do diagrama está totalmente estruturada para fazer frente às necessidades de distribuição ou difusão, em nível local, das empresas oligopolistas nacionais e internacionais situadas à sua esquerda. Como decorrência dessas necessidades, constituem-se localmente empresas de televisão afiliadas das networks, operadoras de TV a cabo ligadas às grandes operadoras nacionais, salas de cinema, videolocadoras, distribuidoras de vídeo, discos, livros para os pontos de venda (lojas, quiosques, livrarias), promotores de eventos locais e rádios. ${ }^{11}$ Quanto maior a dependência em relação à produção externa (como no caso das afiliadas das grandes redes de televisão nacionais), maior a aparente tranquilidade dos seus proprietários em relação ao futuro.

No caso que nos interessa, o mercado de televisão aberta de Sergipe, trata-se de um mercado regional formado por empresas que se limitam basicamente a difundir a programação das cabeças de rede, localizadas principalmente nos estados de São Paulo e Rio de Janeiro, reservando um tímido espaço para a produção local, especialmente nas áreas de jornalismo e esportes. Essa, aliás, é a característica do oligopólio televisivo nacional.

É na década de 1960 que se desenvolve o primeiro marco regulatório geral para os serviços de radiodifusão e de telecomunicações no país, que permanece vigente até

\footnotetext{
${ }^{11}$ Aqui é preciso acrescentar ainda o setor de publicidade, as gráficas e outros serviços eventualmente ligados às diferentes cadeias produtivas da área da comunicação e da cultura, tal como elas se organizam concretamente.
} 
hoje no que se refere ao sistema de televisão aberta. O fato é que a TV de massa no Brasil, desde os seus inícios, assume uma forma de organização essencialmente privada e comercial, formando, desde o final dos anos 1960, um oligopólio altamente concentrado em torno de uma empresa líder que se beneficia desses altos níveis de concentração para lançar-se inclusive na concorrência internacional em condições relativamente vantajosas.

O desenvolvimento de um setor público estatal atenderá, a partir dos anos 1970, quando surge, basicamente ao princípio da "complementaridade marginal" a que se refere Jonas Valente (2009). ${ }^{12}$ Assim, um número restrito de emissoras é responsável por grande parte da produção e distribuição do conteúdo midiático difundido para todo o país, o que lhes confere - e especialmente à líder - não apenas poder de mercado, mas também capacidade de ação política e de lobby.

\section{Os inícios da radiodifusão sergipana}

Em 1939 é implantada a radiodifusão em Sergipe. O interventor federal Eronildes de Carvalho assinou decreto criando a primeira emissora de rádio do estado a Rádio Difusora AM - hoje Rádio Aperipê AM. De caráter estatal, a emissora funcionou, inicialmente, no Palácio do Governo do Estado e posteriormente no Instituto Histórico e Geográfico de Sergipe.

Em 1942, o interventor federal Augusto Maynard Gomes muda o nome para Rádio Difusora de Sergipe PRJ-6 ${ }^{13}$ e a transfere para o Palácio Serigy (MAYNARD, 2008). Sob a tutela do interventor, a emissora é entregue à iniciativa privada, passando a ser dirigida pelo empresário Augusto Luz, então proprietário do cinema Guarany e de um carro de propaganda. A participação da iniciativa privada e o fortalecimento do setor comercial da emissora foram fatores que acompanharam uma tendência nacional da época e tornaram-se fundamentais para a reestruturação da radiodifusão sergipana. Como se sabe, a década de 1940 ficou conhecida como a "era de ouro do rádio",

\footnotetext{
${ }^{12}$ A TV Educativa foi instituída através da Lei 5.198/67. Como lembra Othon Jambeiro (2001), com a mudança do Código Nacional de Telecomunicações, em 1967, as TVs educativas somente poderiam ser operadas pelos governos federal, estadual e municipal, universidades e fundações de direito público. Ao longo do tempo, essas emissoras se organizaram no modelo do broadcasting, em rede nacional, como no sistema comercial. Durante o governo Luís Inácio Lula da Silva (janeiro de 2003 a dezembro de 2010), algumas mudanças foram feitas, às quais nos referiremos adiante, sem alterar, no entanto, significativamente, a situação.

${ }^{13}$ No final da década de 70 a emissora é transferida para a Rua Propriá e logo depois para a Rua Capela. Hoje conhecida como Rádio Aperipê com frequências AM e FM, está localizada na Rua Laranjeiras e faz parte do complexo da Fundação Aperipê.
} 
marcada pela forte atuação das agências de publicidade e pela importação do modelo comercial de gestão norte-americano (MAYNARD, 2008).

Com a intervenção direta de agentes privados, a construção da grade de programação da PRJ-6 passa a ser controlada por interesses particulares, balizando a definição de quais conteúdos seriam produzidos pelos profissionais e de como estes apareceriam durante as transmissões radiofônicas. Essa estruturação institui um modelo de negócio que seria adotado por todo mercado de Rádio e TV em Sergipe nas décadas seguintes.

A Rádio Difusora funcionou sem concorrência durante 14 anos. Somente em 1953, é criada a segunda emissora de rádio em Sergipe, a Rádio Liberdade $\mathrm{AM}^{14}$, de propriedade do industrial Albino Silva da Fonseca. Fundada para fazer oposição ao governo da época, em 1958, com o apoio do Partido Republicano (PR) e do então presidente da República, Juscelino Kubitschek, é criada a Rádio Jornal ${ }^{15}$. Já em 1959, é inaugurada a primeira estação de cunho religioso, a Rádio Cultura AM, emissora idealizada por Dom José Vicente Távora, então bispo de Aracaju. Em 1968, o usineiro e industrial Augusto do Prado Franco inaugura a Rádio Atalaia AM. É somente em 1979 que é criada a primeira emissora de rádio em Frequência Modulada (FM) no estado, a Rádio Atalaia FM 93,5, também de propriedade da família Franco (GOMES, 2009).

\section{A hegemonia da televisão comercial}

As transmissões em TV aberta em Sergipe iniciaram na segunda metade da década de 1960, graças a licenças provisórias que liberaram seu funcionamento em caráter experimental, com transmissões especiais, como a da primeira viagem do homem à Lua, ou jogos de futebol. Tempos depois, o radialista e político Nairson Menezes, com o apoio dos empresários Francisco Pimentel Franco, Josias Passos, Getúlio Passos, José Alves, Hélio Leão, Augusto Santana, Paulo Vasconcelos, Lauro Menezes e Luciano Nascimento, inicia a elaboração do projeto de implantação da primeira emissora de TV em Sergipe (ESTAÇÃO..., nov. 1964, p. 3).

\footnotetext{
${ }^{14}$ A Rádio Liberdade AM, que já pertenceu ao ex-senador Almeida Lima (Partido do Movimento Democrático Brasileiro-PMDB), é dirigida hoje pelo Grupo Torre Empreendimentos, empresa responsável pela coleta de lixo em municípios dos estados de Sergipe e da Bahia (NUNES, 2011).

${ }^{15}$ Atualmente, a Rádio Jornal possui como sócio-diretor o sergipano João Alves Neto, filho do exgovernador João Alves Filho (Partido Democratas-DEM), ex-prefeito de Aracaju (NUNES, 2011). Dantas alerta que, desde sua origem, o rádio foi concebido como uma "tribuna popular, com grande participação do povo em meio, também, a manipulação por parte de determinados useiros dos programas radiofônicos e radialistas que fizeram desses meios de comunicação instrumento de sensacionalismo e de ascensão política" (DANTAS, 2004, p. 292).
} 
Em 15 de novembro de 1971, a empresa Rádio e Televisão de Sergipe Canal 4, na ocasião, repetidora da TV Tupi, conseguiu a licença definitiva para funcionar, com uma grade de programação que iniciava no final da tarde e encerrava a zero hora todos os dias. Esses empresários formaram a primeira diretoria da nova emissora, constituída como Sociedade Anônima, caso único no Brasil. ${ }^{16}$ Dez por cento das ações foram leiloadas ao público e 90\% distribuídas entre os fundadores (A TV..., jul. 1971, p. 8).

A Empire ${ }^{17}$, empresa responsável pela implantação da estação repetidora, doaria os primeiros aparelhos de TV, que foram instalados em pontos estratégicos da capital, locais públicos, como associações e escolas, com o intuito de levar o "bom entretenimento" aos moradores que residiam fora do centro da cidade (ESTAÇÃO..., nov. 1964, p. 3).

A nova TV também possuía um Conselho Consultivo, constituído de dez membros, acionistas ou não. De acordo com a Ata de Assembleia dos acionistas da emissora, publicada no Jornal da Cidade, em novembro de 1973, dentre as responsabilidades desse Conselho estavam a proposição de medidas de orientação à publicidade praticada nas emissoras, levando em conta o interesse local; a sugestão de medidas que visassem o desenvolvimento da sociedade, social e cultural, e a orientação sobre as questões técnicas da emissora (MOTA, 2013).

Correia (2007) lembra que a chegada da televisão no estado estava associada ao progresso da região Nordeste. Naquela mesma década, em Sergipe - principalmente a partir dos investimentos feitos pela Petrobrás nos campos de Carmópolis - inicia-se um processo de reconfiguração social, amparado na ampliação da urbanização. Dantas (2004), por sua vez, destaca que houve um boom no mercado interno fomentado pelo avanço dos meios de comunicação, especialmente com a multiplicação dos aparelhos de TV: “Além dos telefones, os aparelhos de TV multiplicavam-se ano a ano, formando opiniões, alterando atitudes, influenciando as pessoas em suas crenças e valores. Novas exigências de consumo foram se incorporando ao cotidiano das classes média e alta" (DANTAS, 2004, p. 87).

\footnotetext{
16 Além disso, seus dirigentes montaram toda a estrutura com equipamento $100 \%$ nacional. Por outro lado, como os principais anunciantes eram também os principais acionistas, o setor comercial ganhava força frente aos demais.

${ }^{17}$ Conforme autorização do prefeito Godofredo Diniz, a Empire, empresa que já atuava no mercado de rádio no estado e atendia também o mercado nacional, assumiria a responsabilidade pela distribuição dos aparelhos de TV na capital. Um ano depois a Empire, mesmo antes de receber o serviço para implantação da televisão em Aracaju, já vinha se preparando para atuar nesse mercado (ESTAÇÃO..., nov. 1964, p. 3).
} 
Em 1973, a TV Sergipe deixa a Rede Tupi e torna-se afiliada da Rede Globo de Televisão. A adoção do padrão tecnoestético da Globo forçará uma mudança na forma de fazer televisão, à semelhança do que ocorria em todo o país. Com a criação da Globo Nordeste, em 1971, ${ }^{18}$ é implementada uma programação de rede que entende as afiliadas como extensão da sua programação nacional, mesmo quando essas afiliadas pertencem a grandes sistemas de comunicação locais, a exemplo da RBS, do Rio Grande do Sul, e do Sistema Mirante, no Maranhão. Ao obedecer às diretrizes da rede, as afiliadas iniciam a consolidação de um novo modelo, distante da realidade local e homogeneizado nacionalmente (LUSVARGHI, 2009).

Ao se tornar afiliada das Organizações Globo, a TV Sergipe passa por duas significativas mudanças. A primeira diz respeito à adequação ao padrão realizado pela cabeça de rede, que exigiu a implantação de um projeto de reestruturação de equipamentos e das formas de produção, incluindo investimentos na qualificação de pessoal e reformulação do quadro de funcionários, naquela época formado estritamente por profissionais vindos do rádio, do cinema e dos jornais impressos (CORREIA, 2007). A segunda mudança foi uma brusca redução dos conteúdos produzidos localmente. Diante das exigências de recursos decorrentes daquela reestruturação, a emissora viveria a primeira crise financeira, o que causou sua venda em 1976 para o Grupo Aratu da Bahia $^{19}$, o qual, como destacaram Aragão, Menezes e Santos (2006), desenvolvia um projeto audacioso de formar uma rede de televisão no Nordeste.

Um ano antes, no dia 31 de março de 1975, havia sido criada, pelo então governador Augusto Franco $^{20}$, ex-proprietário da TV Sergipe e líder no estado do Partido Aliança Renovadora Nacional (ARENA), a Televisão 31 de Março, conhecida hoje como TV Atalaia. Com sua criação, o mercado de comunicação em Sergipe passaria a ser composto por quatro jornais diários, cinco emissoras de rádio e duas emissoras de TV. Afiliada à TV Tupi, a TV Atalaia foi a primeira emissora local das

\footnotetext{
${ }^{18}$ De acordo com Lusvarghi (2009, p. 8), "a Globo se instala em 1970 com sede própria, sem afiliadas, no Recife, criando a TV Globo de Recife. O projeto de regionalização da Rede Globo fica evidente inclusive dentro da forma como ela se relaciona com os sistemas locais, as organizações mais complexas que integram a rede nacional de cobertura, hospedados em seu website como se fossem extensões departamentalizadas de sua cobertura, tratadas visualmente de forma a diluírem a sua identidade corporativa".

${ }^{19}$ Principal concorrente da TV Itapoã, a TV Aratu, retransmissora da TV Globo na época, entrou no ar em 15 de março de 1969, na gestão do governador Luís Viana Filho (ARENA), com o compromisso de cumprir horários e reforçar a programação local (ARAGÃO; MENEZES; SANTOS, 2006).

${ }^{20}$ A família Franco nessa ocasião não apenas possuía parte da TV Sergipe, mas ocupava cargo de grande relevância na diretoria da emissora. Com isso fica posta em cheque a legalidade da operação de venda da TV Sergipe. A partir de 1976 essa situação se resolve, mas apenas momentaneamente, pois, em 1983, a TV Sergipe volta para as mãos dos Franco.
} 
regiões Norte/Nordeste do Brasil a transmitir programação totalmente colorida (MOTA, 2013).

A TV Atalaia seguiu o exemplo da TV Sergipe e implementou uma programação popular, com quadros culturais, de entretenimento, entrevistas e informação. Mas, ao passo que a TV Atalaia se estruturava, a TV Sergipe caminhava para mais uma crise. No início da década de 1980, a emissora sofreria diversas sanções dos órgãos fiscalizadores do estado, o que geraria intervenções sucessivas da cabeça de rede e a troca da direção do departamento de telejornalismo por três vezes, passando por sérios problemas de gestão (CORREIA, 2007).

Em 1983, a TV Sergipe é revendida à família Franco e passa a concentrar seus esforços no setor de telejornalismo, quase que extinguindo a produção de conteúdo local. É interessante notar que, desde seu retorno para as mãos da família Franco, a TV Sergipe passou, em diferentes momentos, por mudanças técnicas e de gestão, mas essa tendência de privilegiar o conteúdo da matriz não se alteraria, aprofundando-se, aliás, com o passar do tempo (MOTA, 2013).

\section{Da TV Jornal à Canção Nova}

Além da TV Atalaia e TV Sergipe, que concentram a maior parte da audiência até os dias atuais, uma outra emissora foi inaugurada no estado no dia 6 de novembro de 1987: a TV Jornal, filiada à Rede Manchete. A sua concessão foi dada ao político João Alves Filho (então governador pelo Partido Democrátrico Social-PDS, sucessor da ARENA), que ao longo do governo Sarney recebeu outras três concessões de rádio (Rádio Jornal AM e FM de Aracaju, Rádio Jornal de Propriá) (MOTA, 2013). Com as emissoras, o ex-governador passa a ser o principal concorrente da família Franco (PERRINI, 6 nov. 1987, p. 3). Jambeiro (2000) lembra que em 1988, no episódio da aprovação da ampliação do mandato de presidente da República para cinco anos, o governo Sarney, com o intuito de obter apoio parlamentar no Congresso Nacional, concedeu 418 concessões de rádio e televisão. Ao todo, entre 1985 e 1990, a gestão Sarney distribuiu 1028 concessões de rádio e TV, número que representaria 30 por cento do total das outorgas de TV distribuídas no Brasil desde 1922 (JAMBEIRO, 2000).

Em 1993, com a crise da Rede Manchete, a TV Jornal filia-se à Rede Bandeirantes. Tal como as concorrentes, durante seu funcionamento, a TV Jornal transmitiu uma programação popularesca e sem espaço para o conteúdo local. Em 1997, 
a TV Jornal transmitia apenas dois programas locais, o jornal diário Rede Cidade e o programa de debates Batalha da TV ${ }^{21}$ (PROGRAMAÇÃO..., 19 ago. 1987, p. 15).

Em 7 de agosto 1997 é anunciada sua venda para a Rede Canção Nova ${ }^{22}$, negociação que custaria à Igreja 24 parcelas de 500 mil reais. A partir de abril de 1998 a Rede Canção Nova anuncia a programação da emissora de cunho religioso (MARIZ, 2004). Segundo Gasparetto (2005), a emissora, diferentemente das concorrentes, buscava organizar sua audiência e reunir um público que, naquele momento, encontrava-se disperso.

No que se refere ao modelo de financiamento, a sobrevivência da emissora é garantida pelos sócios, que pagam mensalmente uma taxa de contribuição, e pelos produtos vendidos com a marca "Canção Nova". Em 2008, a TV Canção Nova estabeleceu-se como a maior emissora de televisão católica do Brasil, com a marca de um milhão de associados. Destes, $70 \%$ pagam, fielmente, as mensalidades que sustentam a TV e os outros 30\% pagam esporadicamente (GASPARETTO, 2009).

No caso de Aracaju, tal como as outras emissoras comerciais, a programação local da Canção Nova obedece à lógica da programação nacional. Até o início de 2013, os únicos conteúdos produzidos pela TV Canção Nova Aracaju foram matérias jornalísticas diárias e matérias diversas sobre eventos locais ligados à igreja, que são exibidos ao longo da programação nacional e no programa semanal Caminhos de Unidade, apresentado pelo arcebispo de Aracaju, Dom José Palmeira Lessa (MOTA, 2013).

\section{A TV pública sergipana}

A história da TV Aperipê inicia-se em 1972, durante o governo de Paulo Barreto Meneses. Trata-se de uma fundação de caráter público, com autonomia administrativa,

\footnotetext{
${ }^{21}$ O Batalha na TV se transformou no principal programa da TV Jornal. Apresentado pelo jornalista Carlos Batalha, fazia sucesso pelos polêmicos debates com personalidades públicas em torno da política local. Atualmente, o programa é exibido na TV Cidade Aracaju, referida aqui na introdução.

${ }^{22}$ Na década de 1970, surge a Comunidade Canção Nova em Aparecida do Norte, com origens nos encontros de jovens, em Lorena (SP), liderados pelo Padre Jonas Abib. Em 1980, são criadas as rádios Canção Nova AM e FM com "o objetivo de evangelizar por meio de uma programação vasta e sem propaganda comercial" (MARIZ, 2004, p. 08). Somente em 1989 é que a TV Canção Nova realiza suas primeiras transmissões, sendo inaugurada com a transmissão de uma missa, via TVE do Rio de Janeiro. Além das missas, eram transmitidos programas de entrevista e orientação espiritual, todos apresentados pelo monsenhor Jonas Abib. Em 1993, é criada a Editora Canção Nova, que duas décadas depois já havia publicado mais de 100 títulos, com grande parte sendo traduzida para o espanhol e o inglês, comercializados em países latino-americanos, Estados Unidos, Itália e Filipinas. Um marco de sua atuação internacional foi a participação, em 2005, na Feira Internacional do Livro de Frankfurt, a maior do mundo, e na Bienal Internacional do Livro de São Paulo (MARIZ, 2004).
} 
patrimonial e financeira, que reúne hoje uma emissora de TV, Canal $2 \mathrm{VHF}$, e emissoras $^{23}$ de rádio FM e AM. Formalmente, a Fundação Aperipê de Sergipe (Fundap) tem como objetivo promover programas próprios e projetos de desenvolvimento e expansão das ações e atividades de comunicação baseadas em princípios educativos e culturais, de interesse público, sendo vedada a promoção pessoal de autoridades ou servidores públicos. O quadro dirigente é composto por indicados, em comissão, pelo governo do Estado (SERGIPE, jul. 2005).

Somente em 31 de janeiro de 1985, na gestão do governador João Alves Filho (PDS, sucessor da $\mathrm{ARENA}^{24}$ ), entra oficialmente no ar a Televisão Educativa de Sergipe, hoje denominada TV Aperipê, cujo principal objetivo era, segundo Jovino Pinto Filho (2011),

[...] servir como instrumento de formação cultural [...] levando educação à grande massa populacional [...] Tinha como intenção a transmissão de programação educativa variada, com a apresentação de seriados, debates políticos, teatro, música, qualificação profissional e telecurso de $1^{\circ}$ e 2 graus. (PINTO FILHO, 2011, p. 102).

A estratégia de implementação da emissora consistia em explorar os horários de menor audiência das emissoras concorrentes, a TV Sergipe e a TV Atalaia. Por outro lado, tratou-se de ampliar rapidamente a cobertura no estado, chegando a abranger $40 \%$ do território sergipano em apenas dois anos.

Com o slogan "imagem da terra", em 1985 a emissora chegou a transmitir cerca de nove horas de programação local com mais de dez programas diários, sendo a primeira emissora sergipana a fazer transmissões ao vivo, a exemplo dos desfiles do dia da independência e do carnaval da Avenida Barão de Maruim (PINTO FILHO, 2011, p. 51).

Em 1988, sob o governo de Antônio Carlos Valadares (eleito pelo Partido da Frente Liberal-PFL) a emissora passaria por sua primeira crise, ao sofrer significativos cortes no orçamento, os quais a obrigaram a tirar do ar grande parte da programação.

Em 1995, na gestão do governador Albano do Prado Franco (eleito pelo Partido da Social Democracia Brasileira-PSDB), a Fundação é transformada em Instituto de

\footnotetext{
${ }^{23}$ Inaugurada em 12 de dezembro de 1995, a Rádio Aperipê FM, de frequência 104.9, atinge apenas a grande Aracaju, enquanto a Rádio Aperipê AM, inaugurada em 1939, na frequência 630 quilohertz, cobre todo o estado e alguns municípios da Bahia e Alagoas (PINTO FILHO, 2011).

${ }^{24}$ Partido que entre 1964 e 1979 serviu de base de sustentação no Congresso Nacional ao governo militar instituído a partir do golpe de Estado de 1964.
} 
Arte e Educação (Indae) ${ }^{25}$, o que gerou a perda da autonomia administrativa, ficando dependente de verbas da Secretaria de Educação do Estado. Em 2000, no segundo governo de Albano Franco, o Indae é desativado e as emissoras da Fundação Aperipê, realocadas para a Secretaria de Comunicação do Estado. No final de 2001, a Aperipê chega à sua pior fase, sucateada, com cerca de $10 \%$ de programação local e com sinal de transmissão praticamente nulo, devido aos problemas no transmissor (MOTA, 2013).

Em 2003, com o retorno de João Alves Filho ao governo (eleito em 2002 pelo PFL, hoje DEM), a Fundação Aperipê recebe investimento de R\$ 591.409,60 para compra de equipamentos, que possibilitaram o sinal pode chegar a mais de $80 \%$ dos municípios sergipanos (MOTA, 2013). No mesmo ano, o governo federal, sob a presidência de Luiz Inácio Lula da Silva, do Partido dos Trabalhadores, implanta o I Programa de Fomento à Produção e Teledifusão do Documentário Brasileiro $(\mathrm{DOCTV})^{26}$, que garantiu um investimento de cerca de $\mathrm{R} \$ 90$ mil na produção local (PROJETO... 26 set. 2003). A injeção desses recursos na emissora não foi suficiente para estimular de maneira significativa a produção de conteúdo produzido localmente. Segundo pesquisa divulgada em 2006 no I Fórum Nacional de TVs Públicas, 77\% do conteúdo transmitido pela TV Aperipê (e demais emissoras públicas do país) era proveniente da TVE do Rio de Janeiro e da TV Cultura de São Paulo, de forma que acabavam reproduzindo a lógica de estrutura vertical das emissoras comerciais, quando não assumiam o papel de simples repetidoras, o que comprometia a produção local e regional, contrariando os seus objetivos (MINISTÉRIO DA CULTURA, 2006).

A eleição de Marcelo Déda (PT) em 2006 trouxe expectativas de mudanças nas diversas políticas de Estado, incluindo a Fundação Aperipê. Tratava-se da primeira vez em que chegava ao Governo do Estado um agrupamento político progressista, com forte enraizamento nos movimentos sociais da classe trabalhadora sergipana e com um discurso oposto às velhas oligarquias políticas que se revezavam no controle do aparato estatal. Na prática, o governo do PT em Sergipe, assim como em nível federal, em nome da governabilidade, realizou uma política de conciliação, garantindo poucas concessões às reivindicações das classes populares e movimentos sociais, inclusive no tocante às

\footnotetext{
${ }^{25}$ Além das rádios e TV Aperipê, o Indae incorpora também o Conservatório de Música e o Centro de Criatividade.

${ }^{26}$ Com o projeto, os Estados que faziam parte da Associação Brasileira das Emissoras Públicas, Educativas e Culturais (Abepec) teriam mais um espaço para o fomento da cultura local e regional, além da possibilidade de troca de conteúdos ente si. Além disso, todos os documentários produzidos através do DOCTV seriam exibidos aos sábados e deveriam ser reprisados mais duas vezes ao longo da programação.
} 
políticas de comunicação e à TV Pública sergipana. Um ato ilustrativo da política petista frente à emissora pública foi a manutenção de uma estrutura organizacional composta essencialmente por cargos comissionados ocupados por indicações políticas e alheios às demandas sociais. Outro fato para a TV pública sergipana no governo do PT foi a sua vinculação, a partir de 2008, à programação da TV Brasil ${ }^{27}$, que não mudou em nada o regime que já era praticado antes, visto que cerca de $90 \%$ da programação da TV Aperipê era gerada pela TV Cultura de São Paulo e TVE do Rio de Janeiro. Em todo caso, é notável uma mudança qualitativa no que se refere ao conteúdo, inclusive local.

A falta de mudanças estruturais mais profundas, no entanto, mantém a dependência da emissora em relação às frações políticas que compõem os governos de plantão. Com o falecimento de Marcelo Deda, no início do seu segundo mandato, assume o vice, Jackson Barreto, do PMDB, reeleito em 2014. A partir do impeachment da presidenta Dilma Roussef, mudanças importantes ocorrerão também com a TV Brasil e a EBC. Tudo isso afetará evidentemente de forma significativa a TV Aperipê, o que nos obriga a seguir com atenção os acontecimentos daqui por diante.

\section{Considerações finais}

O resultado a que chegamos neste artigo foi um panorama histórico sintético da TV aberta em Sergipe a título de contribuição para os estudos sobre história da mídia no Brasil em perspectiva regional. A partir do arsenal teórico dos estudos de Economia Política da Comunicação desenvolvidos no âmbito do Observatório de Economia e Comunicação da Universidade Federal de Sergipe desde os anos 1990, cuja matriz original é o trabalho de Bolaño (1988), e com base no estudo mais amplo apresentado no livro Mercado Brasileiro de Televisão em perspectiva regional: O caso de Sergipe (BOLAÑO; VARJÃO, 2016) empreendemos aqui uma análise abreviada desde a história da constituição das principais emissoras de TV aberta - TV Sergipe, TV Atalaia,

\footnotetext{
${ }^{27}$ Em 10 de outubro de 2007, por meio da Medida Provisória n o 398, de 2007, o presidente Luiz Inácio da Silva criou a Empresa Brasil de Comunicações (EBC), órgão vinculado à Secretaria de comunicação do Governo Federal. Com isso, deixaram de existir a Radiobras, a TV Nacional, a TVE Rio de Janeiro, a TVE do Maranhão, TV Brasil São Paulo, Rádio Nacional e Rádio MEC e o seu sítio informativo na internet. Valente (2009, p. 7) explica que a criação da EBC "marca a retomada de um projeto de TV Pública que responde à tendência de operação de um aparato centralizado experimentado anteriormente na figura da Radiobras, e absorve a lógica de rede tendo como vértice a TVE do Rio de Janeiro". Acrescenta que a criação da rede também representou "um novo momento da chamada TV Pública brasileira, com um projeto de cunho nacionalizante e com intenções de construir um espaço mais equilibrado, embora não assumidamente contra-hegemônico" (VALENTE, 2009, p. 134).
} 
TV Aperipê e Canção Nova - no estado até as principais tendências de atuação das emissoras existentes nas últimas décadas.

De maneira geral, concluímos que o mercado de televisão aberta em Sergipe é formado por empresas que se limitam basicamente a difundir a programação das cabeças de rede, localizadas principalmente nos estados de São Paulo e Rio de Janeiro, reservando um tímido espaço para a produção local, especialmente nas áreas de jornalismo e esportes. A posição subalterna e dependente que a economia brasileira e, especialmente a sergipana, historicamente ocupa na divisão internacional do trabalho nos dá a chave para compreender as razões da adoção de sistemas industriais que atuam no sentido de atender às necessidades das empresas oligopolistas nacionais e internacionais.

Submetido em 30.11.2016

Aceito em 13.04.2017

\section{REFERÊNCIA BIBLIOGRÁFICA}

ARAGÃO, Joanna M.; MENEZES, Juliana C. F. de; SANTOS, Lourivânia, S. Caixa mágica: um resgate da história da TV em Salvador. 2006. Trabalho de Conclusão de Curso (Curso de Jornalismo) - Faculdade Social da Bahia, Salvador, Bahia, 2006.

A TV será uma realidade. Gazeta de Sergipe, Aracaju, ano XVI, n. 4.488, p. 8, jul. 1971.

BOLAÑO, César Ricardo Siqueira. Mercado brasileiro de televisão. Aracaju: Editora UFS, 1988.

BOLAÑO, César (Org.). Economia política da internet. São Cristóvão: Editora UFS, 2007.

BOLAÑO, César; VARJÃO, Demétrio (Coord.). Mercado brasileiro de televisão em perspectiva regional: o caso de Sergipe. São Cristóvão: Observatório de Economia e Comunicação da Universidade Federal de Sergipe, 2016.

CORREIA, Luciano dos Santos. TV Caju e TV Cidade, o conteúdo local no mercado de televisão por assinatura em Aracaju. 2007. 178 f. Dissertação (Mestrado em Ciências da Comunicação) - Programa de Pós-Graduação em Ciências da Comunicação, Universidade do Vale do Rio dos Sinos (Unisinos), São Leopoldo, 2007. Disponível em: <http://www.repositorio.jesuita.org.br/bitstream/handle/UNISINOS/2621/TV\%20Caju $\% 20 \mathrm{e} \% 20 \mathrm{TV} \% 20 \mathrm{Cidade}$.pdf? sequence=1\&isAllowed=y>. Acesso em: 21 mar. 2011 .

DANTAS, Ibarê. História de Sergipe República (1889 - 2000). Rio de Janeiro: Tempo 
Brasileiro, 2004.

ESTAÇÃO de tevê virá mesmo a Sergipe. Sergipe Jornal, Aracaju, n. 14.371, p. 3, nov. 1964.

GASPARETTO, Paulo Roque. Midiatização da religião: processos midiáticos e a construção de novas comunidades de pertencimento: estudo sobre a recepção da TV Canção Nova. 2009. 197 f. Tese (Doutorado em Comunicação) - Programa de PósGraduação em Ciências da Comunicação, Universidade do Vale do Rio dos Sinos (Unisinos), São Leopoldo, 2009.

TV Canção Nova: a midiatização do neodevocional. 2005. 115 f. Dissertação (Mestrado em Ciências da Comunicação) - Programa de Pós-Graduação em Ciências da Comunicação, Universidade do Vale do Rio dos Sinos (Unisinos), São Leopoldo, 2005.

GOMES, Rafael de J. Rádio digital: as perspectivas para a implantação do sistema envolvendo as rádios FM's de Aracaju/SE. 2009. 57 f. Monografia (Departamento de Comunicação Social) - Universidade Federal de Sergipe, São Cristóvão, Sergipe, 2009.

JAMBEIRO, Othon. Regulando a TV: uma visão comparativa no Mercosul. São Paulo: Hacker, 2000.

A TV no Brasil do século XX. Salvador: EDUFBA, 2001.

LUSVARGHI, Luiza. A reinvenção do Nordeste: estratégias dos grupos de mídia para o jornalismo audiovisual regional. Revista Alterjor, São Paulo, ano 1, v. 1, ago./dez. 2009. Disponível em: <http://www.revistas.usp.br/alterjor/article/view/88180 >. Acesso em: 02 abr. 2013.

MARIZ, Cecília L.. "Comunidades de vida no espírito santo": um novo modelo de família? In: CONGRESSO LUSO-AFRO-BRASILEIRO DE CIÊNCIAS SOCIAIS, 8., 2004, Coimbra. Anais... Coimbra: Universidade de Coimbra, 2004. Disponível em: <http://www.ces.uc.pt/lab2004/inscricao/pdfs/painel18/CeciliaMariz.pdf>. Acesso em: 15 mar. 2012.

MAYNARD, Dilton Cândido Santos. Entre microfones e bastidores: Estado Novo, radiodifusão e intervenção cultural em Sergipe. Revista Cadernos de Pesquisa. Centro de Documentação e Pesquisa em História do Instituto de História da Universidade Federal de Uberlândia, Uberlândia, v. 1, n. 35, jul./dez. 2008. Disponível em: <http://goo.gl/GORHT>. Acesso em: 11 set. 2011.

MINISTÉRIO DA CULTURA. I Fórum Nacional de TVs Públicas: diagnóstico do campo público de televisão: caderno de debates. Brasília, DF, 2006.

MOTA, Joanne Santos. Mercado sergipano de televisão aberta: 40 anos depois, onde está o conteúdo regional? 2013. 108 f. Monografia (Departamento de Comunicação Social) - Universidade Federal de Sergipe, São Cristóvão, 2013.

NUNES, Cláudio. Caixa-Preta: "donos" no papel das rádios em SE. Infonet, Cidade, Aracaju, 31 maio 2011. Disponível em: 〈http://goo.gl/h2FHI $>$. Acesso em: 10 out. 
2011.

PERRINI, Paulo. TV-Jornal é inaugurada. Jornal de Sergipe, Aracaju, ano IX, n. 2.757, p. 3, sexta-feira, 6 nov. 1987.

PINTO FILHO, Jovino. Estratégias em empresas de comunicação: o caso da Fundação Aperipê de Sergipe. 2011. 72 f. Monografia (Bacharelado em Administração) - Curso de Graduação em Administração, Universidade Federal de Sergipe, São Cristóvão, 2011.

PROGRAMAÇÃO da TV jornal. Jornal da Cidade, Aracaju, ano IX, nº 7.530, p. 15, sexta-feira, 19 ago. 1987.

PROJETO vai financiar a realização de documentário sergipano. Infonet. Aracaju, 26 set. 2003.2 Disponível em: <http://www.infonet.com.br/noticias/cidade/ler.asp?id=18307>. Acesso em: 02 jul. 2012.

SERGIPE (Estado). Lei n. 5.696, de 15 de junho de 2005. Dispõe sobre nova organização básica da Fundação Aperipê de Sergipe-FUNDAP/SE, e dá providências correlatas. Diário Oficial do Estado de Sergipe, Poder Executivo, Aracaju, n. 24816, 18 jul. 2005.

VALENTE, Jonas Chagas Lúcio. A criação da TV Brasil e sua inserção no modo de regulação setorial da televisão brasileira. 2009. 97 f. Dissertação (Mestrado em Comunicação) - Programa de Pós-Graduação em Comunicação, Universidade de Brasília, Brasília, 2009. 